\title{
Self-Esteem, Academic Self-Concept, and Aggression at School
}

\author{
Laramie D. Taylor $^{1 *}$, Pamela Davis-Kean ${ }^{2}$, and Oksana Malanchuk ${ }^{2}$ \\ ${ }^{1}$ University of California at Davis, Davis, California \\ ${ }^{2}$ University of Michigan, Ann Arbor, Michigan
}

: : : : : : : : : : : : : : : : : : : : : : : : : : : : : : $: 1:$ : $:$ :

The present study explores the relation between academic self-concept, self-esteem, and aggression at school. Longitudinal data from a racially diverse sample of middle-school students were analyzed to explore how academic self-concept influenced the likelihood of aggressing at school and whether high self-concept exerted a different pattern of influence when threatened. Data include self-reported academic self-concept, school-reported academic performance, and parent-reported school discipline. Results suggest that, in general, students with low self-concept in achievement domains are more likely to aggress at school than those with high self-concept. However, there is a small sample of youth who, when they receive contradictory information that threatens their reported self-concept, do aggress. Global self-esteem was not found to be predictive of aggression. These results are discussed in the context of recent debates on whether self-esteem is a predictor of aggression and the use of a more proximal vs. general self-measure in examining the self-esteem and aggression relation. Aggr. Behav. 33:130-136, 2007. (C) 2006 Wiley-Liss; Inc.

: : : : : : : : : : : : : : : : : : : : : : : : : : : : : : : :

\section{INTRODUCTION}

School violence is an insidious problem-while occasional, large-scale tragedies, particularly school shootings, garner most of the media attention, more mundane acts of aggression are common occurrences in today's schools. Some schools and school districts have attempted to diminish such aggression through programs intended to foster self-esteem among students, based on the notion that low selfesteem is a contributing cause of aggression. This assumption has been called into question by recent research using adult samples which has failed to find a link between self-esteem and aggression, and by recent theorizing which suggests that if anything, narcissism, generally associated with high rather than low self-esteem, contributes to aggression [Bushman and Baumeister, 1998]. Other recent research, however, has supported the findings that low self-esteem is, indeed, what predicts children's aggression [Donnellan et al., 2005]. Thus, it is unclear what the role of self-esteem is in predicting aggression in children. The present study seeks, then, to clarify the link between self-esteem and aggression by testing in a diverse sample of youth, the predictability of aggression from different levels of self-esteem (high and low). In addition, we will test whether self-esteem, when threatened, predicts to aggression.

\section{Self-Esteem and Aggression}

Conventional wisdom is that aggression often arises from low self-esteem. Numerous rationales for such a connection have been offered, including the possibility that aggression is used to improve low self-esteem. One study found members of gangs score lower on measures of self-esteem and higher on measures of aggression than demographically matched youth [Kee et al., 2003]. Similarly, selfreported self-esteem and aggression, in a sample of adolescents, were found to be negatively correlated [Fling et al., 1992]. Recently, research by Donnellan et al. [2005] found that low self-esteem predicted aggression in a sample of adolescents and young adults. These finding were replicated across multiple methods (e.g., laboratory experiments) and multiple studies.

This link is not universally supported, however. Baumeister et al. [2000], for example, observe that in many cases, groups of individuals who are relatively more aggressive also have relatively high self-regard,

\footnotetext{
*Correspondence to: L.D. Taylor, Department of Communication, University of California at Davis, One Shields Avenue, Davis, CA 95616 USA. E-mail: lartaylor@ucdavis.edu
}

Received 22 March 2005; Accepted 1 December 2005

Published online 6 February 2007 in Wiley InterScience (www.inter science.wiley.com). DOI: 10.1002/ab.20174. 
including muderers, rapists, people under the influence of alcohol, and individuals in the manic phase of bipolar disorder. Although high self-esteem itself has not been implicated as a cause of aggression, related constructs such as egotism and narcissism, particularly when threatened, have. Theoretically, egotism is threatened when favorable self-views or high self-esteem is challenged by discrepant information, and a choice is made. If the threatened individual rejects the discrepant information, she or he will experience negative emotions toward the source of the ego threat. These emotions increase the likelihood of aggressing against that source [Baumeister et al., 1996]. Although it is generally agreed that high self-esteem does not in and of itself promote aggression for most individuals, it has been suggested that some subset of individuals high in self-esteem are in fact basically insecure, their apparent high self-esteem largely bluster [Salmivalli, 2001]. Such individuals may also be described as having high but unstable self-esteem [Kernis, 2001].

\section{Self-Esteem, Narcissism, and Self-Concept}

In order to clearly discuss the nature of egotismaggression link, it is important to parse out how a number of related but distinct constructs are similar to and distinct from self-esteem, and how each is likely to relate to aggression. The most important of these concepts is narcissism. While self-esteem is generally conceptualized as a global assessment of one's own worth, narcissism is a sense of entitlement and superiority. An individual with high self-esteem thinks she or he is good; a narcissistic individual thinks she or he is better. Individuals who score high on measures of narcissism are likely to score similarly high on measures of self-esteem, though the reverse is not necessarily true.

Narcissism is clearly associated with increased aggression. In a series of laboratory experiments, those who scored high in narcissism responded more aggressively to rejection than did those low in narcissism, while general self-esteem did not moderate participants' reaction to rejection [Twenge and Campbell, 2003]. Similarly, Bushman and Baumeister [1998] found that, in a sample of adults, narcissism was associated with aggression, while self-esteem was not. It is possible that narcissism rather than high self-esteem is linked to aggression, and that some portion of the null results in explorations of a self-esteem-aggression link are due to the correlation between self-esteem and narcissism.
Another concept closely related to self-esteem is self-concept. Self-concept is the cognitive representation an individual has of him- or herself. For the purposes of this discussion, we will focus on evaluative elements of self-concept, or the cognitive evaluation of one's abilities or traits [Salmivalli, 2001]. For example, while someone with high selfesteem feels good about her- or himself overall, her or his self-concept may include the belief that she or he is good at math but terrible at competitive sports. Evidence suggests that positive self-concept is closely associated with positive self-esteem [Farmer et al., 2001]; people who believe that they are good at a lot of things tend to feel better about themselves overall. It is unclear whether this occurs as people use their cognitive assessments of their abilities to form a global assessment of themselves or as people make positive inferences about their specific skills and abilities based on their overall assessments of their own worth.

It is possible that a negative self-concept in a particular domain such as academic ability may be associated with increased aggression, at least in contexts relevant to that domain (i.e., school). When that domain is made salient (such as when a child is at school), a poor self-concept may be experienced as or lead to an aversive emotional state, which has long been known to be associated with an increased likelihood of aggression [Berkowitz, 1993]. Aggression may also be employed in an attempt to improve self-concept in other domains in order to compensate for a poor self-concept in the initial area; the child may see her or his lack of scholastic ability as less important in light of her or his manifest physical strength or power.

Self-concept on academic ability may also be associated with aggression due to common causes. Students with relatively lower IQ, for example, are likely to have poor self-concepts on academic ability and are also more likely to be aggressive [Huesmann et al., 1987]. Alternately, students who are aggressive may experience difficulty learning and, as a result, develop a poor self-concept on academic ability.

The recent theoretical suggestions that threatened egotism may lead to increased aggression leading to another important question: What happens when a positive self-concept is threatened? According to Baumeister et al. [1996], when positive self-views are challenged, individuals are more likely to aggress. Although they make this assertion in reference to global self-esteem, a positive self-concept is also a positive self-view, and perhaps would have a stronger influence due to its more domain-specific relation to any given behavior (e.g., math, science, sports). 
Little research has explicitly explored possible connections between self-concept, as opposed to self-esteem, and aggression. One small study found no correlation between global self-concept and aggression among elementary-aged children [Schaughency et al., 1987]. To date, no published research has examined a link between domainspecific self-concept and aggression in related contexts.

Thus, in the present study, we seek to explore how self-esteem and self-concept may influence aggression in a school setting. Specifically, we pose the following research question and hypotheses:

RQ1: How will overall self-esteem influence children's likelihood of committing acts of aggression in school?

H1: Students with less favorable academic selfconcept will be more likely to commit acts of aggression in school than children with more favorable academic self-concept.

$\mathrm{H} 2$ : Students whose high academic self-concept is threatened will also be more likely to commit acts of aggression in school than other children.

\section{METHODS}

\section{Overview}

In order to explore the question of how self-esteem and self-concept influence aggression, we analyzed longitudinal data on middle-school children. The impact of general self-esteem, academic self-concept, and potential threats to academic self-concept on the likelihood of committing acts of aggression at school were assessed, controlling for general aggression and a history of aggression at school.

Data used in the analysis were collected as part of a large, longitudinal study of adolescents. Students enrolled in middle schools in a racially and socioeconomically diverse county in an East-coast state were recruited for participation. During seventh grade, participants completed interviews and selfadministered questionnaires. In addition, each child's parent or primary caregiver was interviewed and completed a self-administered questionnaire about the child. These interviews and questionnaires were repeated during eighth grade. Further, school records were obtained for each participant. More detail on methods and sample are available elsewhere [Roeser et al., 1998].

\section{Sample}

The sample includes youth who participated in a long-term panel study beginning during their middle-school years. Information sufficient for all analyses reported in this paper was available for 842 children, just over half of whom were male $(51.1 \%)$. The sample was racially diverse; nearly $2 / 3$ of the children reported their race as Black or African American, and $1 / 3$ as White or Caucasian. All participants were enrolled in middle school in the same county in an East-coast state. The first wave of data was collected at the beginning of the school year when participants were enrolled in seventh grade, and the second at the beginning of eighth grade.

\section{Definitions and Methods of Data Collection}

Aggression. Aggression is defined as the deliberate infliction of harm on another person. Aggression may be physical, such as pushing or hitting, psychological, such as taunting or threatening, or social, such as defaming or spreading rumors. In order to focus only on more serious aggression, only acts of aggression which resulted in formal school discipline were included in the analysis. As part of a larger questionnaire, parents were asked to indicate whether their child had been disciplined at school (i.e., been suspended or received detention) at any point prior to seventh grade (wave 1) or during the past year (in other words, at any point during seventh grade) (wave 2). Parents who responded affirmatively were asked to indicate why their child was so disciplined. Children were coded as being disciplined for school violence if their parents reported at least one aggressive behavior as the cause of school discipline. These behaviors included fighting, hitting another student, shoving another student, bringing a weapon to school, threatening a teacher, and shoving a teacher. According to these parental reports, $22 \%$ of all participants had been disciplined at school for aggressive behavior at school at some time during their seventh-grade year.

Self-esteem. As part of longer questionnaires, students completed measures of general self-esteem and self-concept of academic abilities (SCA). General self-esteem (SE) was measured using six items about students' satisfaction with who they were and their behavior adapted from the general self-worth subscale of Harter's [1982] Perceived Competence Scale for Children. Questions included "How often would you like to change lots of things about you if you could?" (reverse scored) and "How happy are you with the way you act?" Participants responded 
to each question on a scale of $1-5$, and responses to all six items were averaged to obtain a single score $(M=3.67, \mathrm{SD}=.79)(\alpha=.80)$.

Self-concept of academic abilities. SCA was measured using several questions which asked students to indicate how well they did in math and school in general, both in absolute terms and when compared to other kids in their school on a scale of 1 ("not at all good" or "much worse than other kids") to 7 ("very good" or "much better than other kids"). These questions were derived from the cognitive portion of the PCSC. Responses were averaged to form a single score $(\alpha=.78)$; the average score suggests that participants generally believed themselves to be above average $(M=5.33$, $\mathrm{SD}=1.07)$.

Academic performance. Each participant's grade-point average, or GPA, for the seventh-grade year was obtained from school records $(M=3.13$, $\mathrm{SD}=.58)$. Given the timing of the first and second waves of data collection, seventh-grade GPA represents the grades students would have received after the first wave and before the second, or during their seventh-grade academic year. We note that this particular operationalization is, for the purposes of the present analysis, a proxy for the ongoing academic feedback received by participants throughout the course of the year. A low GPA reflects low grades on periodic report cards, which in turn reflect low grades, scores, and marks on tests and assignments throughout the grading period.

Threat to self-concept. The idea of threatened high self-esteem has been offered as one possible way in which high self-esteem may contribute to aggression. For our study, we conceptualized threatened high self-esteem in terms of academic performance. We reasoned that students who rated themselves very highly on academic self-concept and subsequently performed very poorly in school would essentially experience the receipt of proof of their poor performance (low grades) as a threat to their high self-esteem. In the present study, threatened self-concept was operationalized in terms of the interaction between GPA (reverse-scored) and selfconcept on academic ability, so that higher scores were indicative of the co-occurrence of stronger beliefs in one's own academic ability and superiority and poor academic performance. Students with the highest interaction are those with the most inflated academic egos that have been threatened by negative academic feedback. Similarly, the interaction between overall self-esteem and low GPA was included to explore the possibility that general self-esteem rather than domain-specific self-esteem may lead to increased likelihood of aggression.

It is important to note that, given the constraints of the data, there is no clear time sequence for the experience of negative academic feedback and discipline for school aggression. The two were essentially measured concurrently. This limits the ability to draw causal inferences from the results of the present analysis. However, establishing a relationship between negative academic feedback and increased aggression that can be explored for individuals who vary on self-concept and self-esteem is still valuable.

Aggression-related controls. General aggression was controlled for in two ways. First, previous history of school discipline for aggression as reported by each participant's primary caregiver was entered as a control. A total of 118 participants were reported to have been so disciplined in the years prior to the beginning of the study. In addition, participants completed a measure of anger which was included as a control. The measure consisted of a series of four items in which participants were asked to indicate how frequently they feel angry, such as "How often have you felt so angry you wanted to smash or break something?" and "How often have you felt that you couldn't control your temper" on a scale from 1 (almost never) to 5 (almost always) $(M=2.35, \mathrm{SD}=.90)$ $(\alpha=.81)$.

\section{Analysis}

After computing bivariate correlations among the relevant variables (see Table I), binary logistic regression was selected as the method of analysis with being disciplined at school for aggression as the dependent variable. The possibility of a non-monotonic relationship between the self-esteem measures and the likelihood of school aggression was addressed by squaring both academic self-concept and self-esteem and including the results in the analysis.

\section{RESULTS}

Correlations were observed between school aggression during seventh grade and many of the expected predictors (see Table I). Being a Black male was associated with a greater likelihood of school aggression, or at least for being disciplined therefore, as were both aggression controls. Higher SES was associated with a diminished likelihood of school aggression. Self-concept on academic ability was negatively correlated with school aggression, as 
TABLE I. Correlations Among School Aggression and its Predictors

\begin{tabular}{|c|c|c|c|c|c|c|c|c|c|c|c|}
\hline & W2 SD & $\mathrm{BM}$ & $\mathrm{BF}$ & WM & SES & W1SD & ANG & SCA & SE & GPA & $\mathrm{SCA} \times \operatorname{GPA}(r)$ \\
\hline BM & $.25^{*}$ & & & & & & & & & & \\
\hline $\mathrm{BF}$ & -.06 & $-.5^{*}$ & & & & & & & & & \\
\hline WM & -.06 & $-.32^{*}$ & $-.30^{*}$ & & & & & & & & \\
\hline SES & $-.17^{*}$ & $-.08^{*}$ & $-.10^{*}$ & $.13^{*}$ & & & & & & & \\
\hline W1SD & $.40^{*}$ & $.16^{*}$ & $-.08^{*}$ & -.02 & $-.08^{*}$ & & & & & & \\
\hline ANG & $.20^{*}$ & $.07^{*}$ & .04 & -.02 & $-.09^{*}$ & $.15^{*}$ & & & & & \\
\hline SCA & $-.12^{*}$ & -.01 & .01 & .00 & $.10^{*}$ & -.05 & $-.19^{*}$ & & & & \\
\hline SE & -.02 & $.07^{*}$ & $-.07^{*}$ & $.10^{*}$ & .03 & -.01 & $-.36^{*}$ & $.24^{*}$ & & & \\
\hline GPA & $-.29^{*}$ & $-.21^{*}$ & .05 & .03 & $.18^{*}$ & $-.21^{*}$ & $-.18^{*}$ & $.29^{*}$ & $.07^{*}$ & & \\
\hline $\mathrm{SCA} \times \operatorname{GPA}(r)$ & $.26^{*}$ & $.24^{*}$ & $-.06^{*}$ & -.05 & $-.17^{*}$ & $.20^{*}$ & $.11^{*}$ & .03 & .02 & $-.93 *$ & \\
\hline $\operatorname{SE} \times \operatorname{GPA}(r)$ & $.26^{*}$ & $.23^{*}$ & $-.08^{*}$ & -.01 & $-.15^{*}$ & $.18^{*}$ & .03 & $-.17^{*}$ & $.32 *$ & $-.90^{*}$ & $.89^{*}$ \\
\hline
\end{tabular}

Note: $7 \mathrm{SD}=$ disciplined for aggression at school during seventh grade; $\mathrm{BM}=$ Black males; $\mathrm{BF}=$ Black females; $\mathrm{WM}=\mathrm{White}$ males.

*Correlations are statistically significant at $P<.05$.

was GPA. Consistent with the threatened-egotism hypothesis, the interactions between low GPA and higher academic self-concept and higher overall selfesteem were positively associated with a greater likelihood of school aggression.

Other observed correlations generally support the notion that higher self-esteem is associated with lower levels of aggression; a strong negative association was observed between anger and both academic self-concept and overall self-esteem. On the other hand, there was no significant correlation between prior school aggression and either of these.

The correlations between these various factors and school aggression, although interesting, are of limited value in that many of the predictors are also correlated with each other. In order to better parse out these relationships, all predictors were entered as covariates in a binomial logistic regression with being disciplined for aggression at school during seventh grade as the dependent variable. Demographic controls remained strong predictors; being either a Black male or a White male was predictive of increased likelihood of being disciplined for aggression at school, although for White males this finding is only marginally significant (see Table II for coefficients). Relatively lower SES was also associated with a greater likelihood of aggression. Past acts of aggression in school settings were found to be the strongest predictor of an increased likelihood of school aggression during the study period; greater anger as reported by participants was also associated with a greater likelihood of being disciplined for aggression at school.

Of the various self-concept and scholastic predictors, however, only academic self-concept remained a significant predictor of school aggression. Both the simple and quadratic academic self-concept
TABLE II. Binary Logistic Regression Model Predicting the Likelihood of Being Disciplined for Aggression at School

\begin{tabular}{lccc}
\hline & $B$ & SE $B$ & Odds ratio \\
\hline Black male & $1.38^{* * *}$ & .35 & 3.99 \\
Black female & .56 & .36 & 1.74 \\
White male & $.74^{*}$ & .41 & 2.10 \\
SES & $-.30^{*}$ & .12 & .74 \\
Previous school & $2.59^{* * *}$ & .34 & 13.31 \\
aggression & & & \\
Anger & $.35^{* *}$ & .11 & 1.42 \\
SCA & $-1.56^{*}$ & .67 & .21 \\
SCA & $.12^{*}$ & .06 & 1.12 \\
SE & .95 & .72 & 2.59 \\
SE & -.15 & .10 & .86 \\
GPA & .89 & .90 & 2.44 \\
SCA $\times$ GPA $(r)$ & .26 & .16 & 1.30 \\
SE $\times$ GPA $(r)$ & .09 & .18 & 1.09 \\
\hline
\end{tabular}

Significant at $P<.10$.

* Significant at $P<.05$.

** Significant at $P<.01$.

*** Significant at $P<.001$.

terms were significant, the latter only marginally. Higher self-concept on academic ability at the beginning of seventh grade predicted a lower likelihood of being disciplined for aggression at school during the ensuing year; the marginally significant squared term suggests that this may not be true of those with the highest self-concept.

In order to explore the possibility that low GPA did not pose a threat to academic self-concept, an OLS regression was conducted in which academic self-concept at the beginning of seventh grade, GPA at the end of seventh grade, and their interaction predicted academic self-concept at the beginning of the following year $(F(3,839)=76.60, P<.001)$. The results suggest that after controlling for prior academic self-concept $(B=.44, \mathrm{SE}=.04, P<.001)$, 
a higher GPA has a positive effect on academic self-concept $(B=.10, \mathrm{SE}=.05, P<.05)$, and the coincidence of low GPA and higher prior academic self-concept predicts lower self-concept $(B=-.03$, $\mathrm{SE}=.01, P<.05)$.

\section{DISCUSSION}

Overall self-esteem was found, in the present study, to be unrelated to aggression in school. This is consistent with other research which has shown that, while narcissism is associated with aggression, global self-esteem generally is not. This is not particularly surprising when we consider that global self-esteem may arise from many different factors, many of which are entirely independent of the school setting. Some children likely have self-esteem that depends largely on family, spiritual life, or hobbies. There is little reason to believe that experiencing deleterious outcomes in any of these domains is likely to lead to aggression in the unrelated domain of school. It seems more likely that aggression would arise in the domain from which it derives its source.

Our first hypothesis, that low scholastic selfconcept would be associated with a greater likelihood of school violence, was generally supported. Students with less positive perceptions about their own scholastic abilities were more likely to aggress in school than those with more positive perceptions, even after controlling for actual scholastic ability as indicated by GPA. Of course, this conclusion is tempered somewhat by the apparent likelihood that at some point, very high academic self-concept is actually associated with a greater likelihood of aggression. One possibility is that this upward curve may reflect the overlap between academic selfconcept and narcissism that has been demonstrated to predict aggression. The fact that the same pattern is not observed for self-esteem is interesting, but not contradictory. For the overall self-esteem measure, participants indicated their perceptions of their own worth in absolute terms - how happy they are with themselves, and so on. For the academic selfconcept measure, participants also indicated how they perceive themselves in relative terms-how smart and capable they are relative to their peers. Thus the academic self-concept measure is more likely to have captured some measure of narcissism than the self-esteem measure. Again, given the marginal significance of the quadratic term, however, we must be cautious in interpreting this finding.
Importantly, our hypothesis that threatened academic self-concept would be associated with a greater likelihood of aggressing at school was not supported. Inasmuch as low grades pose a threat to students with either high academic self-concept or high overall self-esteem, experiencing threats to selfconcept or self-esteem does not seem to increase the likelihood of aggressing, at least in the school setting.

This collection of findings is important for a number of reasons. First, by including both global and domain-specific self-constructs, this analysis allows insight into the nature of the impact of both on aggression. The present study partially replicates Bushman and Baumeister's [1998] finding that global self-esteem is not related to aggressionoverall self-esteem was unrelated to school aggression. It offers further clarification, however, in that it demonstrates a relationship between domainspecific self-concept and aggression relative to that domain.

Second, our findings suggest that, due to the nonmonotonic relationship observed between academic self-concept and school aggression, interventions that target self-concept should be somewhat tailored to their recipients. For the majority of children, low self-concept is linked to an increased likelihood of aggression, apparently independent of academic ability. Thus, improving self-concept in specific domains and giving appropriate academic intervention may well reduce the likelihood of school aggression for individual children.

These conclusions are somewhat tempered by the limits of the study itself, of course. Though the study utilizes longitudinal data, it is not an experiment, and thus causal conclusions cannot be made; furthermore, academic feedback and school aggression were measured concurrently. Second, our operationalization of threatened high academic self-concept, while high in face validity, is indirect. It is possible that some students who perceive themselves as superior to their peers academically do not experience the receipt of low grades as a threat to this perception. Third, we explore only a single domain of self-esteem; in order to better understand the relationship between self-concept, self-esteem, and aggression, future research should explore other domains as well, beginning with those domains in which children's aggression is more frequent or perhaps more problematic such as the family.

In addition, we recognize the limitations of the primary dependent variable. Not all aggressions at school lead to school discipline. One possible 
explanation of the observation that being a Black male leads to a dramatically higher likelihood of being disciplined for aggression at school is that persistent racial stereotypes about Black males lead to an increased likelihood or severity of discipline for Black males than for White males or for any females, regardless of offense. Unfortunately, these are issues that cannot be explored with the present data.

Even given these limitations, however, this study adds to a growing literature that suggests that low self-esteem is still an important predictor of aggression in youth, and that it would be premature to neglect this area of research when trying to unravel the antecedents of aggression.

\section{REFERENCES}

Baumeister RF, Smart L, Boden JM. 1996. Relation of threatened egotism to violence and aggression: The dark side of high selfesteem. Psychol Rev 103:5-33.

Baumeister RF, Bushman BJ, Campbell WK. 2000. Self-esteem, narcissism, and aggression: Does violence result from low selfesteem or from threatened egotism? Curr Dir Psychol Sci 9:26-29.

Berkowitz L. 1993. "Aggression: Its causes, Consequences, and Control," Boston, MA: McGraw-Hill.

Bushman BJ, Baumeister RF. 1998. Threatened egotism, narcissism, self-esteem, and direct and displaced aggression: Does self-love or self-hate lead to violence? J Pers Soc Psychol 75:219-229.
Donnellan MB, Trzesniewski KH, Robins RW, Moffitt TE, Caspi A. 2005. Low self-esteem is related to aggression, antisocial behavior, and delinquency. Psychol Sci 16:328-335.

Farmer RF, Jarvis LL, Berent MK, Corbett A. 2001. Contributions to global self-esteem: The role of importance attached to selfconcepts associated with the five factor model. J Res Pers 35: 483-499.

Fling S, Smith L, Rodriguez T. 1992. Videogames, aggression, and self-esteem: A survey. Soc Behav Pers 20:39-45.

Harter S. 1982. The perceived competence scale for children. Child Dev 53:87-97.

Huesmann LR, Eron LD, Yarmel PW. 1987. Intellectual functioning and aggression. J Pers Soc Psychol 52:232-240.

Kee C, Sim K, Teoh J, Tian CS, Ng KH. 2003. Individual and familial characteristics of youths involved in street corner gangs in Singapore. J Adolescence 26:401-412.

Kernis MH. 2001. Following the trail from narcissism to fragile selfesteem. Psychol Inquiry 12:223-225.

Roeser RW, Eccles JS, Sameroff AJ. 1998. Academic and emotional functioning in early adolescence: Longitudinal relations, patterns, and prediction by experience in middle school. Dev Psychopathol 10:321-352.

Salmivalli C. 2001. Feeling good about oneself, being bad to others? Remarks on self-esteem, hostility, and aggressive behavior. Aggr Violent Behav 6:375-393.

Schaughency E, Frame CL, Strauss CC. 1987. Self-concept and aggression in elementary school students. J Clin Child Psychol 16:116-121.

Twenge JM, Campbell WK. 2003. 'Isn't it fun to get the respect that we're going to deserve?" Narcissism, social rejection, and aggression. Pers Soc Psychol B 29:261-272. 